\title{
Determinants of agricultural technology adoption under partial population awareness: the case of pigeonpea in Malawi
}

\author{
Franklin Simtowe ${ }^{1 *}$, Solomon Asfaw ${ }^{2}$ and Tsedeke Abate ${ }^{1}$
}

\author{
* Correspondence: \\ f.simtowe@cgiar.org \\ IInternational Maize and Wheat \\ Improvement Center (CIMMYT), \\ ICRAF House, United Nations \\ Avenue, 1041-00621, Nairobi, Gigiri, \\ Kenya \\ Full list of author information is \\ available at the end of the article
}

\begin{abstract}
There is exhaustive literature on technology adoption rates and the relationship between technology adoption and relevant socioeconomic and policy variables. Yet adoption estimates derived from the application of standard techniques such as the probit and tobit yield biased estimates. This paper applies the modern evaluation technique: the counterfactual outcome framework to data from about 400 households in Malawi to assess the patterns of diffusion and adoption of improved pigeonpea varieties and their determinants. We find the sample adoption rate of improved varieties to be $14 \%$ while the potential adoption rate if the improved varieties were widely disseminated is estimated at $41 \%$. The adoption gap resulting from the incomplete exposure to the improved pigeonpea is $27 \%$. Moreover, adoption is also found to be high among female-headed households, older farmers and those with access to credit. The findings suggest that for increased adoption, there is need for increased involvement of extension workers is the dissemination of information about improved pigeonpea varieties, a robust pigeonpea seed system to increase seed availability to farmers as well as the need for improved access to credit.
\end{abstract}

Keywords: Pigeonpea, Diffusions, Adoption, Average treatment effect, Malawi

\section{Background}

Technology adoption studies are mainly focused on estimating adoption rates and understanding the relationship between technology adoption, its intensity and relevant socioeconomic, and policy variables. While such studies are quite useful in explaining some of the bottlenecks to technology adoption, they yield biased estimates of both adoption rates as well as determinants of adoption when applied to a population that is not fully aware of the technology. This is because although awareness is an important precondition for adoption to occur, farmer knowledge of the improved varieties is neither random nor universal and may suffer from selection bias. This fact also suggests that the relationship between awareness and adoption cannot be linearly specified. Indeed Diagne and Demont (2007) empirically show that when a technology is new and the target population is not universally exposed to it, the observed sample adoption rate is not a consistent estimator of the true population adoption rate. It

\section{Springer}

(c) 2016 Simtowe et al. Open Access This article is distributed under the terms of the Creative Commons Attribution 4.0 International License (http://creativecommons.org/licenses/by/4.0/), which permits unrestricted use, distribution, and reproduction in any medium provided you give appropriate credit to the original author(s) and the source, provide a link to the Creative Commons license, and indicate if changes were made. 
suffers from what is known as "nonexposure"1 bias and it yields inconsistent and biased estimates of population adoption rates even when based on a randomly selected sample.

Diagne and Demont (2007) show why taking the adoption rates within the subsample of farmers exposed to the technology does not address the selection bias problem and why such population estimates are not consistent estimates of the true population adoption rate even if the sample is random. Such estimates may underestimate or overestimate the true population adoption rate. In fact, the sample adoption rate among the exposed is likely to overestimate the true population adoption rate because of a positive population selection bias by which the subpopulation most likely to adopt gets exposed first.

In this paper we provide a micro-perspective of the potential adoption rates and the determinants of adoption of improved pigeonpea varieties among farmers from southern Malawi. Given the low levels of awareness of improved pigeonpea varieties we do not expect high adoption rates by farmers randomly sampled for this study. Moreover, the interest in this paper is to assess the potential for adoption (potential demand) of these technologies by the farmers once they get fully exposed to them and once other exogenous factors are taken into account.

Pigeonpea (Cajanus cajan) is one of the most versatile and multipurpose dryland legume crops with enormous potential for wide adoption by the farming communities in the semi-arid tropics as a cash as well as food crop. Originated from India and moved to Africa about 4,000 years ago, it is one of the many grain legumes being cultivated in Malawi where pigeonpea farmers consume up to $70 \%$ of the total production, and sell about $30 \%$ of it to generate cash income Orr et al. (2013). Pigeonpea ranks as the third most important legume crop after groundnut and beans in the period of 1991-2009 in Malawi. The 78,000 tons of pigeonpea produced per year, accounted for $23 \%$ of Malawi's total legume production (Simtowe et al. 2009).

Pigeonpea is widely grown as an intercrop with maize in southern Malawi, but it is mainly grown as a boundary marker in northern Malawi. Although known for its soil fertility enhancement attributes, Snapp et al. (2002) report that farmers are primarily interested in pigeonpea as a market crop and as a weed suppression agent and that soil fertility benefits are secondary. As expressed by Orr et al. (2015) Malawi was formerly the world's largest exporter of pigeonpea but its share in the world market has fallen because of yield losses from Fusarium wilt. Pigeonpea exports from Malawi reach Mumbai, India before the Indian harvest in October, when prices are highest. Exports comprise both dry grain and de-hulled and split grain (Tur dhal). India's imports of pigeonpea are projected to reach 636,000 tonnes by 2020 (Abate et al., 2012), providing Malawian growers an opportunity to increase exports.

The Malawi government policy on pigeonpea aims at promoting the production, consumption and marketing of pigeonpea for food security, income and soil fertility improvement. It is meant to be grown as either an intercrop in the maize farming systems or as a pure stand Malawi Government (2006). To achieve this goal, the government has established a strong pigeonpea improvement program aimed at breeding and disseminating improved pigeonpea varieties. In collaboration with the International Crops Research Institute for the Semi-Arid Tropics (ICRISAT) and other national partners, a number of improved pigeonpea varieties have been developed and released as a 
way of improving pigeonpea productivity and competitiveness in Malawi. Two long duration (ICP 9145 and ICEAP 00040) and two short duration (ICPL 93027 and ICPL 87105) varieties were released for wider cultivation. Each of the released varieties has economically important traits that make it attractive to smallholder farmers. ICP 9145 (released in 1987) and ICEAP 00040 (released in 2000) are resistant to Fusarium wilt and harbour high on farm yield potential of up to 1.9 tons/ha (Høgh-jensen et al. 2007). The short duration varieties are less tolerant to Fusarium wilt but have an added advantage in that they can be consumed as grain as well as a vegetable. Their capacity to mature early also makes them more suited for the semi-arid regions and provides an opportunity for double cropping in regions with long or bimodal rainfall seasons.

However, the improved varieties have not been widely disseminated and are not widely known and adopted by the farming communities. Consistent with this expression, Freeman et al. (2002) report that although new pigeonpea technologies are available, their dismal adoption by the farming community in Malawi has been due to the lack of knowledge about their existence. The continued use of local and inferior varieties has led to the low pigeonpea yields of around $500 \mathrm{~kg}$ per hectare. Efforts to improve the diffusion of improved pigeonpea varieties are widely seen as panacea to the widely acknowledged problems of low rates of adoption. Moreover, beyond the lack of awareness, there are other constraints to the adoption of improved pigeonpea varieties that have not been fully understood and addressed for adoption to take place.

We follow Diagne and Demont (2007) to address this problem by employing a programme evaluation methodology based on counterfactual outcomes to provide unbiased estimators of the rate of adoption and the factors affecting adoption. The rest of the paper is organized as follows: Pigeonpea production and utilization in Malawi discusses pigeonpea production and significance while the data and analytical methodology are described in Methods. The results and discussions are presented in Results and discussions, while section Conclusions.

\section{Pigeonpea production and utilization in Malawi}

In Malawi, pigeonpea is grown by smallholder farmers for both local consumption and export. Malawi remained one of the largest producers of pigeonpea in Africa in the period 1991-2006, producing about 78,000 metric tons per year, which accounted for about $28 \%$ of the continent's production. While Malawi's past pigeonpea trends in harvested area, production, productivity and exports have been positive, and while the global demand for pigeonpea continues to rise, the extent to which Malawian and African farmers benefit from these markets will rely on the extent to which improvements in productivity growth and market development help offset threats of intense competition for export markets (mainly India) from Myanmar and other emerging producers, as well as the surging demand for other substitutes (e.g. yellow pea produced mainly in Canada and France).

The bulk of pigeonpea production is concentrated in the southern region of the country (Fig. 1) where pigeonpea occupies a significant proportion of the farming system, contributing up to about $20 \%$ of farmers' income (Orr. A, S.Orr 2002). The Blantyre and Machinga Agricultural Development Divisions account for about $90 \%$ of the total pigeonpea area cultivated. Pigeonpea is widely grown as an intercrop with maize in southern Malawi, but it is mainly grown as a boundary marker in northern Malawi. 


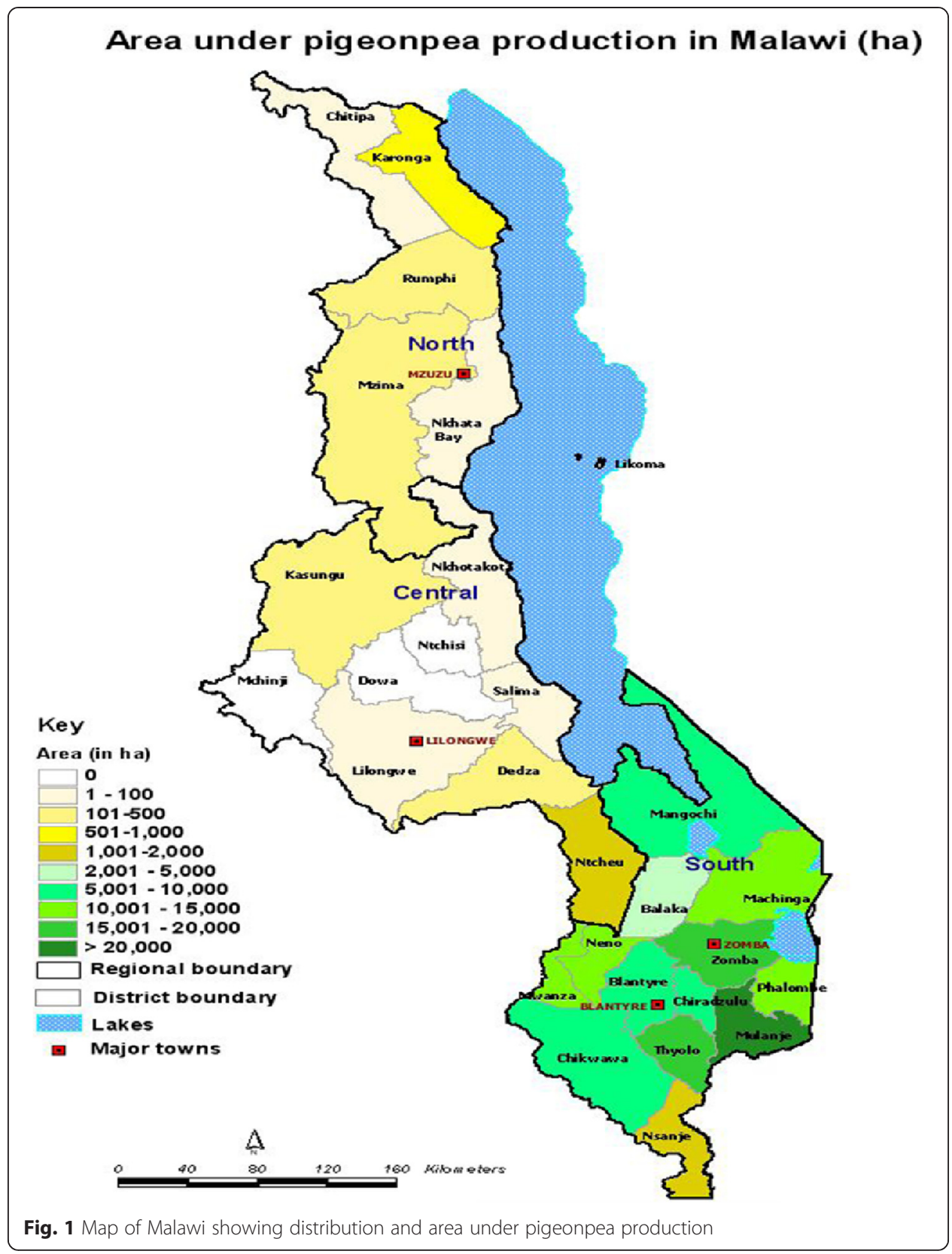

Although known for its soil fertility enhancement attributes, Snapp et al. (2002) report that farmers are primarily interested in pigeonpea as a market crop and as a weed suppression agent and that soil fertility benefits are secondary.

With regards to utilization, Muwalo et al. (1999) report that an estimated $65 \%$ of the pigeonpea produced in Malawi is consumed on-farm by the farm households either as cooked dry peas or as immature pods and green seeds cooked as vegetables. The consumption rate is similar to that of Kenya but substantially higher than the consumption rate of $35 \%$ reported for Tanzania. Lo Monaco (2003) attributes the low on-farm consumption rates in Tanzania to the high integration of producers in the market channels. An estimated $10 \%$ of Malawi's pigeonpea production is sold to the domestic market while $25 \%$ is exported. 


\section{Methods}

\section{Theoretical approach ${ }^{2}$}

The analysis in this paper is guided by a theoretical framework of technology adoption under partial population exposure proposed by Diagne and Demont (2007). The framework is relevant in this analysis because although a number of pigeonpea varieties have been released and disseminated in Malawi, a very small fraction of the farming population has been exposed to the technologies. Furthermore, exposure to the improved pigeonpea by farmers was not random. Applying the treatment framework allows us to control for both non-exposure and selection biases and helps in estimating true population adoption rates and the determinants of adoption. The treatment variable in this paper is "exposure" or "awareness" of at least one variety of improved pigeonpea such that those exposed to improved pigeonpea are considered as "treated", while those unaware are considered "untreated".

First proposed by Rubin (1974) the average treatment effect (ATE) parameter measures the effect or impact of a "treatment" on a person randomly selected in the population Wooldrige (2002) In the context of this study "treatment" corresponds to exposure to a technology and the ATE on the adoption outcomes of population members is the population mean adoption outcome. This is the population mean adoption outcome when all members of the population have been exposed to a technology and it is, therefore, a measure of the intrinsic value of the technology as indicated by its potential demand by the population. In that sense, the population mean adoption outcome measured by the ATE parameter is the population mean potential adoption outcome.

The difference between the population mean potential adoption outcome and the mean actual (i.e. observed) adoption outcome, which is in fact the combined mean of population exposure to and adoption of the technology, is the population non-exposure bias. This is also known as the population adoption gap, because it measures in some sense the unmet population demand for the technology. It is assumed that the gap exists because of the incomplete diffusion of the technology in the population (Diagne and Demont 2007). Similarly, the mean adoption outcome in the exposed subpopulation corresponds to what is defined in the treatment effect literature as the average treatment effect on the treated, (i.e. the mean effect of a treatment in the treated subpopulation), commonly denoted as ATE1 or ATT Wooldrige (2002) The difference between the population mean adoption outcome (ATE) and the mean adoption outcome among the exposed (ATE1) is the population selection bias (PSB). The consistent estimation of ATE and ATE1, which are the main focus of the treatment effect methodology, requires controlling appropriately for the exposure status. The details of the estimation procedures of the ATE parameters in the adoption context are given in Diagne and Demont (2007).

Following Rosenbaum and Rubin (1983) and Wooldrige (2002), let $y_{1}$ be the potential adoption outcome of a farmer when exposed to improved pigeonpea varieties and $y_{0}$ be the potential adoption outcome ${ }^{3}$ when not exposed to them. The "treatment effect" for the farmer $\boldsymbol{i}$ is the measure by the difference $y_{1 i}-y_{0 i}$ Hence the expected population adoption impact of exposure to the new varieties is given by the mean value $E\left(y_{1}-y_{0}\right)$. However, as expressed by Diagne and Demont (2007) since exposure to a new variety is a necessary condition for its adoption, we have $y_{0}=0$ for all farmers not exposed. 
Hence the adoption impact of the farmer $i$ is given by $y_{1 i}$ and the average adoption impact (of exposure) is given by $A T E=E y_{1}$. The problem is that we observe $y_{1}$ only for the farmers exposed to the new varieties. In impact evaluation literature this is referred to as the problem of missing data. There is a problem of missing data because it is not possible to measure the impact on the same individuals, as at each moment in time, each individual is either under the intervention being evaluated or not and thus he or she can not be in both. This implies that we cannot observe the outcome variable of interest for the targeted individuals had they not been exposed to the new variety at the same time.

In this paper, let us assume the binary variable $w$ to be an indicator for exposure to the improved varieties where $w=1$ denotes exposure to at least one improved variety and $w=0$, otherwise. The estimation of adoption rates and its determinants can be done based on the observed random vectors $\left(\left(y_{i}, w_{i}, x_{i}, z_{i}\right) i=1, \ldots . ., n\right)$ from a random sample of the population; where $\boldsymbol{x}_{i}$ is the vector of covariates that determines potential adoption outcome (the value of $y_{1}$ ) and $z_{i}$ is the vector of covariates that determine exposure (the value of $\boldsymbol{w}_{1}$ ) with the possibility of $x_{i}$ and $z_{i}$ having some common elements.

The ATE methodology enables the identification and consistent estimation of the population mean adoption outcome $E\left(y_{1}\right)$ and the population mean adoption outcome conditional on a vector of covariates $x E\left(y_{1} \mid x\right)$, which in this framework corresponds to the conditional population mean adoption outcome (ATE) denoted usually as ATE $(x)$ (Wooldrige 2002 chapter 18). One approach to the identification of ATE is based on the so-called conditional independence assumption (Wooldrige 2002, chapter 18) also referred to as the ignorability assumption, which states that the treatment status $w$ is independent of the potential outcomes $y_{1}$ and $y_{0}$ conditional on the observed set of covariates $z$ that determine exposure $(w)$. This can be expressed as $P\left(y_{1}=1 \mid z\right) ; i=0,1$.

The ATE parameters identified through the conditional independence assumption can be estimated from observed random vectors $\left(y_{1}, w_{i}, x_{i}, z_{i}\right)_{i=1, \ldots, n}$ from a random sample of the population either using pure parametric regression based-methods where covariates are possibly interacted with treatment status variable (to account for heterogeneous impacts) or they are based on a two-stage estimation procedure where the conditional probability of treatment $P(w=1 \mid z) \equiv P(z)$, called the propensity score, is estimated in the first stage and the ATE is estimated in the second stage by parameric or nonparametric methods (Diagne and Demont 2007).

In addition to the conditional independence assumption, it is assumed that potential adoption is independent from $z$, conditional on $x: P\left(y_{1}=1 \mid x, z\right)=P\left(y_{1}=1 \mid x\right)$. Thus we can be able to implement the estimation of adoption rate and its determinants from the exposed sub sample alone, if the conditional independence assumption holds and if potential adoption is independent of vectors of exposure determinants conditional on the vector of adoption determinants. Then the ATE (x) can be nonparametrically identified from the joint distribution of $(\mathrm{y}, \mathrm{z})$ condition on $w=1$ by:

$$
\operatorname{ATE}(x)=\mathrm{E}(y \mid x, w=1)
$$

This can be consistently estimated from a random sample of $y_{i}, x_{i}=1, \ldots n$ drawn from the exposed subpopulation only. 
The parametric estimation procedure of ATE is based on the following equation that identifies $\operatorname{ATE}(x)$ and which holds under the conditional independence (CI) assumption (see Diagne and Demont 2007):

$$
\operatorname{ATE}(x)=\mathrm{E}\left(y_{1} \mid x\right)=\mathrm{E}(y \mid x, w=1)
$$

The parametric estimation proceeds by first specifying a parametric model for the conditional expectation in the right hand side of the second equality of equation (2) which involves the observed variables $y, x$ and $w$ :

$$
\mathrm{E}(y \mid x, w=1)=g(x, \beta)
$$

where $g$ is a known (possibly nonlinear) function of the vector of covariates $x$ and the unknown parameter vector $\beta$ which is to be estimated using standard Least Squares (LS) or Maximum Likelihood Estimation (MLE) procedures using the observations $\left(y_{i}, x_{i}\right)$ from the subsample of exposed farmers only with $y$ as the dependent variable and $x$ the vector of explanatory variables. With an estimated parameter $\hat{\beta}$, the predicted values $g\left(x_{i}, \hat{\beta}\right)$ are computed for all the observations $i$ in the sample (including the observations in the non-exposed subsample) and ATE, ATE1 and ATE0 are estimated by taking the average of the predicted $g\left(x_{i}, \hat{\beta}\right) i=1, \ldots, n$ across the full sample (for ATE) and respective subsamples (for ATE1 and ATE0):

$$
\begin{aligned}
& A \hat{T} E=\frac{1}{n} \sum_{i=1}^{n} g\left(x_{i}, \hat{\beta}\right) \\
& A \hat{T} E=\frac{1}{n_{e}} \sum_{i=1}^{n} w_{i} g\left(x_{i}, \hat{\beta}\right) \\
& A \hat{T} E 0=\frac{1}{n-n_{e}} \sum_{i=1}^{n}\left(1-w_{1}\right) g\left(x_{i}, \hat{\beta}\right)
\end{aligned}
$$

As also expressed by Diagne and Demont (2007) the effects of the determinants of adoption as measured by the $K$ marginal effects of the $K$-dimensional vector of covariates $x$ at a given point $\bar{x}$ are estimated as:

$$
\frac{\partial E\left(y_{1} \mid \bar{x}\right)}{\partial x_{k}}=\frac{\partial g(\bar{x}, \hat{\beta})}{\partial x_{k}} \quad k=1, \ldots, K
$$

where $x_{k}$ is the $k^{\text {th }}$ component of $x$.

In our empirical analysis below, we have estimated the ATE, ATE1, ATE0, the population adoption gap $(G \hat{A} P=J \hat{E} A-A \hat{T} E)^{4}$, and the population selection bias $(P \hat{S} B=A \hat{T} E 1-A \hat{T} E)$ parameters using the parametric regression based estimators (equations 4,5 , and 6 ).

The estimation of the determinants of exposure is important for its own sake as it can provide valuable information regarding the factors influencing farmers' exposure to a new technology. These factors, which are mostly related to the diffusion of information, can very well be different from those influencing the adoption of the technology once exposed to it (Diagne and Demont 2007). In our estimation of the parametric regression based estimators, since $y$ is a binary variable, equation 3 above is effectively a parametric probabilistic model. We, therefore, have $E(y \mid x, w=1)=P(y=1 \mid x, w=1)$ 
with an assumption of a probit model, $g(x, \beta)=\Phi(x \beta)$.In this case the parametric estimation of ATE reduces to a standard probit estimation restricted to the exposed sub-sample. The marginal effects in equation (7) are also estimated using this ATE parametric model. The estimation was done in STATA using a STATA routine developed by Diagne (2012).

\section{Data}

The data used in this analysis were collected by the International Crops Research Institute for the semi-Arid Tropics (ICRISAT), in collaboration with the Centre for Agricultural Research and Development (CARD) of the University of Malawi and the National Smallholder Farmer's Association (NASFAM) in between April and May 2008, in Malawi. The data were collected through a household survey conducted in the three districts of Chiradzulu, Thyolo, and Balaka. A multi stage sampling procedure was employed in selecting households for the survey. The first stage involved a purposeful sampling of the three districts that are among the major growing areas of pigeonpea in the southern Malawi. Once the districts were selected, the second stage involved a purposeful selection of four largest pigeonpea producing sections ${ }^{5}$ in each district. Consequently this led to the selection of 12 sections for the study area. Third, a complete list of all the villages in each section was drawn with the help of the heads of Extension Planning areas (EPA) and their staff. Three (3) villages were randomly selected from each section. Fourth, and last a complete list of all farm families was then drawn for each of the randomly sampled villages. Thirteen (13) farmers were randomly sampled from a list of farm families in each village. This led to the selection of 440 households for the household survey. Data were collected at village and at farm-household levels. At the village level, data collected included crops grown, prices offered for crop produce, and the village infrastructures. At the farmer level data collected included the farmer knowledge of varieties and varieties cultivated in 2006/07. Prior to the survey a list of known modern and traditional varieties in the village was constructed and each farmer selected for the survey was asked whether he or she knew each of the varieties and crops. If the answer to the question was a 'yes' then the farmer was asked whether he or she had ever cultivated the variety and if he or she cultivated it in 2006/07 season. In the present study we define knowledge or exposure to a variety as a "yes" answer to the first question and adoption as the cultivation of the variety.

\section{Results and discussions}

\section{Farm household characteristics}

Table 1 reports descriptive statistics disaggregated by their adoption status for 440 surveyed farmers. Adopters are defined as households that planted at least one variety of improved pigeonpea during the 2006/07 cropping season. Improved pigeonpea varieties were grown by $14 \%$ of the sampled households in 2006/07 cropping season. About three-quarters of the households were male-headed, and the proportion of maleheaded households was higher among non-pigeonpea growing (72\%) than among the sub-sample of pigeonpea growers (66\%). The difference was significant at $5 \%$ probability level. This observation suggests that improved pigeonpea cultivation is highly preferred by female farmers. The average household size for the sampled households is 4.8 
Table 1 Household characteristics by adoption status of improved pigeonpea in 2006/07

\begin{tabular}{|c|c|c|c|c|}
\hline Characteristic & $\begin{array}{l}\text { Non-adopters } \\
(n=381) 86 \%\end{array}$ & $\begin{array}{l}\text { Adopters } \\
(n=59) 14 \% \\
\end{array}$ & $\begin{array}{l}\text { Total } \\
(n=440)\end{array}$ & Difference \\
\hline \multicolumn{5}{|l|}{ Socio-demographic factors } \\
\hline Proportion of male farmers & $72.3(2.1)$ & $66.1 .4(2.9)$ & 72.5.1(2.1) & $7.7(3.5)^{* *}$ \\
\hline Age & $45.3(0.91)$ & $45.9(2.3)$ & $45.4(0.84)$ & $-0.60(2.48)$ \\
\hline Household size & $4.6(0.10)$ & $5.2(0.28)$ & $4.8(0.09)$ & $-0.5(0.28)^{*}$ \\
\hline Years of residence in the village & $30.4(1.00)$ & 29.6(1.22) & $30.1(0.77)$ & $0.83(1.5)$ \\
\hline Land holding size & $2.1(0.7)$ & $3.1(2.3)$ & $2.3(0.1)$ & $-0.9(0.2)^{* * *}$ \\
\hline Off-farm income (MK) & $16682(1679)$ & $58464(21409)$ & 22298(3287) & $-42781(9440)^{*}$ \\
\hline Value of assets (MK) & $5856(729)$ & 9627(3790) & $6362(810)$ & $-3770(2374)$ \\
\hline \multicolumn{5}{|l|}{ Education and experience farming } \\
\hline Years of schooling & $4.9(0.19)$ & $5.1(0.24)$ & $5.0(0.15)$ & $-0.18(0.30)$ \\
\hline Years of experience in pigeonpea farming & $15.1(0.66)$ & $18.3(0.94)$ & $15.5(0.7)$ & $-3.2(1.1)^{*}$ \\
\hline Years of experience in groundnut farming & $8.6(0.57)$ & $12.3(0.91)$ & $8.7(0.49)$ & $-4.1(1.0)^{* *}$ \\
\hline \multicolumn{5}{|l|}{ Institutional factors } \\
\hline Proportion farmers with access to credit & $15.2(2)$ & $33(6)$ & $17.7(1.1)$ & $-18(5)^{* * *}$ \\
\hline Distance to village market & $2.7(0.13)$ & $0.73(0.19)$ & $2.4(0.1)$ & $1.91(0.36)^{* * *}$ \\
\hline Distance to the farmer club & $0.15(0.03)$ & $0.03(0.02)$ & $0.41(0.03)$ & $0.13(0.09)$ \\
\hline Distance to an agricultural office & $4.5(0.14)$ & $4.7(0.37)$ & $4.6(0.13)$ & $-0.04(0.39)$ \\
\hline Contacts with government extension & $5.6(0.78)$ & $2.8(0.90)$ & $5.3(0.77)$ & $2.11(2.1)$ \\
\hline Contacts with NGO extension worker & $1.8(0.8)$ & $0.46(0.15)$ & $1.2(0.48)$ & $1.33(1.0)$ \\
\hline Membership in faith based organization (\%) & $51(20)$ & $0.50(14)$ & $12.5(1.3)$ & $12.5(2.7)^{* * *}$ \\
\hline Membership in a farmer's club & 7.6(1.3) & 13.6(4.4) & $8.4(1.3)$ & $5.9(3.8)$ \\
\hline
\end{tabular}

Source: ICRISAT Treasure Legumes/TLII Study (April- May 2008)

Data with asterisk Indicates that difference between adopters and non-adopters is statistically significant at $95 \%$ level (t-tests are used for differences in means). *indicates significance at $10 \%$. ${ }^{*}$ indicates significance at $5 \% .{ }^{* *}$ indicates significance at $1 \%$

persons per household. This is slightly higher than the national average of 4.4 persons per household (National Statistics Office, 2005). Adopting households have significantly (at $10 \%$ probability level) larger households (5.2 persons) than the non-adopting households ( 4.6 persons). The average land holding size for the sampled households is 2.3 acres (equivalent to 1 hectare) and adopting households have significantly larger portions of land (3.1 acres) than the non-adopting households ( 2.1 acres). The education level of the household's head is expressed in terms of years of schooling and it is not significantly different between adopters and non-adopters. It is also observed that adopting households have a significantly high amount of household off-farm income (MK58,464) than non-adopting households (MK16682). More adopters (33\%) reported having access to credit ${ }^{6}$ than non adopters $(15 \%)$. Access to markets was measured by capturing distances to the village market. The average distance to the village market is 2.4 kilometres. Adopting households have a significantly shorter distance $(0.7 \mathrm{~km})$ to the market, than nonadopting households $(2.7 \mathrm{~km})$, which suggests that market access could have an effect on the adoption status of a farm-household. There are no significant differences between adopters and non-adopter in the degree of access to extension services. Member ship in social groupings such as in faith based organization is more pronounced among adopters (13\%) than non-adopters (7 \%) suggest a positive correlation between adoption and membership in a social grouping. 
Pigeonpea diffusion and adoption: a descriptive analysis

In this paper, we use the concept "diffusion" to imply awareness or knowledge of the improved pigeonpea varieties by the farmers. In the adoption literature, however, the terms "diffusion" and "adoption" are mostly used interchangeably. (see for example Feder et al., 1985; Rogers, 1976; Sunding \& Zilberman, 2001). Feder et al. (1985) describe technology adoption as a multistage process the decision maker undergoes from the time they get exposed to the technology (become aware of its existence) through to the time that they decide to start using the technology. Central to the adoption decisions is the role of information about the technology.

As depicted in Fig. 2, the adoption process starts with the potential adopter becoming aware of the existence of a technology. The second stage involves a process of information acquisition, through which the potential adopter gets to know technology attributes and builds up his or her perceptions (positive or negative) about the technology. While this phase determines whether the producer has heard about the new technology of pigeonpea on not, it is also a learning phase during which the potential adopter gets to understand the attributes of a technology further. Consistent with this notion, Klotz et al. (1995) posit that a producer's optimal information level is the solution to an underlying utilitymaximization problem characterized by an income-leisure trade-off and that conditional upon the producer being aware of a new technology, the decision of whether or not to adopt the new technology is made. The third stage involves trial or experimentation by the potential adopter before adopting the technology. Based on perceived benefits of the technology, the individual goes through the fourth stage which involves the actual technology adoption. Once the technology is adopted, the adopter may decide to continue using it or discontinue depending on the experience and benefits after adoption. In this paper we follow the definition of Feder et al. (1985) of adoption as the decision to use an innovation in long-run equilibrium given full information about its potential. We thus confine the definition of adoption to the growing of one or more improved pigeonpea varieties by a farmer.

Table 2 depicts results of pigeonpea varieties widely known by farmers. There is as a universal awareness (99 \%) of at least one pigeonpea (local + improved) variety by the respondents. However, the awareness rate for improved pigeonpea varieties (ICP 9145 locally known as Sauma -literally translated as "doesn't dry" in reference to its drought torelance and ICEAP 00040- locally known as Kachangu- which can be translated_as "quick" in reference to its early maturity) is much lower, estimated to be $34 \%$ of the total sample. Knowledge of improved pigeonpea varieties is more prevalent in Thyolo (47\%) and Balaka (49\%).

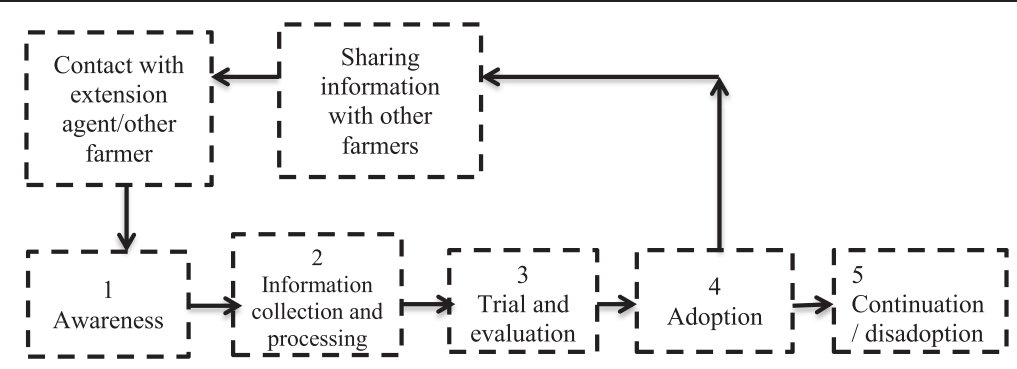

Fig. 2 Stages of the adoption process. Source: Adopted with some modifications from Phillips (2008) 
Table 2 Diffusion and adoption of pigeonpea: Proportion of farmers that were aware and those that adopted different pigeonpea varieties in 2006/2007

\begin{tabular}{|c|c|c|c|c|}
\hline Characteristic & $\begin{array}{l}\text { Chiradzulu } \\
(n=152)\end{array}$ & $\begin{array}{l}\text { Thyolo } \\
(n=144)\end{array}$ & $\begin{array}{l}\text { Balaka } \\
(n=144)\end{array}$ & $\begin{array}{l}\text { Total } \\
(n=440)\end{array}$ \\
\hline \multicolumn{5}{|l|}{ Know the variety (\%) } \\
\hline Local (miscellaneous) & 95 & 94 & 97 & 95 \\
\hline Mthawajuni & 99 & 25 & 90 & 71 \\
\hline ICEAP 00040 & 4 & 40 & 39 & 28 \\
\hline ICP 9145 & 1 & 8 & 25 & 11 \\
\hline Know at least one pigeonpea variety & 100 & 98 & 100 & 99 \\
\hline Know at least one improved variety & 5 & 47 & 49 & 34 \\
\hline Ever planted (\%) & & & & $!$ \\
\hline Local(miscellaneous) & 63 & 87 & 80 & 77 \\
\hline Mthawajuni & 99 & 17 & 76 & 64 \\
\hline ICEAP 00040 & 3 & 31 & 38 & 24 \\
\hline ICP 9145 & 0 & 6 & 19 & 8 \\
\hline \multicolumn{5}{|l|}{ Planted in 2006/07 season (\%) } \\
\hline Local (miscellaneous) & 7 & 73 & 49 & 43 \\
\hline Mthawajuni & 97 & 10 & 70 & 59 \\
\hline ICEAP 00040 (Kauma) & 3 & 25 & 27 & 18 \\
\hline ICP 9145 (Kachangu) & 0 & 4 & 13 & 6 \\
\hline Planted at least one pigeonpea variety & 43 & 33 & 87 & 54 \\
\hline Planted at least one improved variety & 2 & 5 & 33 & 14 \\
\hline \multicolumn{5}{|c|}{ Planted in 2006/07 season (\% of the exposed sub-sample) } \\
\hline Planted at least one pigeonpea variety & 43 & 34 & 87 & 55 \\
\hline Planted at least one improved variety & 33 & 10 & 66 & 36 \\
\hline
\end{tabular}

Source: ICRISAT Treasure Legumes/TLII Study (April- May 2008)

Of the two improved varieties, ICEAP 00040 is the most widely known (20\%) while ICP 9145 is only known by $8 \%$ of the farmers. These findings are indicative of a failure and inefficiency of the system through which technologies are disseminated in Malawi hence suggesting the need for intensified dissemination efforts to promote the technologies. There is an opportunity for ICRISAT to use existing structures for government extension services to disseminate the information to farmers in potential pigeonpea grown areas.

Although more respondents expressed awareness of the varieties, fewer reported ever growing them and a much smaller proportion of them actually grew the crop in 2006/ 2007 season. For local pigeonpea although $71 \%$ of the farmers expressed some knowledge of the crop, only $57 \%$ reported that they ever grew it and only $31 \%$ grew the crop in the 2006/2007 season. For Mthawajuni variety, 53 \% know the crop, 48 \% indicated that they ever grew the crop, while $44 \%$ actually grew it in 2006/2007. As for the improved varieties, farmers are more aware of ICEAP 00040 (20\%) and $18 \%$ have ever grown it but only $13 \%$ grew it in 2006/2007. In general, $54 \%$ of the sample households reported that they grew at least one variety (local/improved) of pigeonpea in 2006/07, however only $14 \%$ grew at least one improved variety of pigeonpea. It is also interesting to note that there are smaller proportions of households growing the varieties in 2006/07 than those that ever grew, indicating that there is some form of dis-adoption 
for almost all varieties. Although, this paper does not explore causes of dis-adoption, this is an important area of research to be investigated. This presence of dis-adoption is expected as some farmers might have been trying or experimenting on the technology before fully deciding on whether or not to adopt.. Consistent with this observation, Rogers (2003) observes that there are five stages in the adoption process namely; (a) knowledge, (b) persuasion, (c) decision, (d) implementation, and (e) confirmation. An adopter may discontinue the use of the technology for a number of reasons including economic constraints as well as changes in preferences.

These sample adoption rates are likely to be biased downwards because they include farmers who were not yet exposed to the varieties and, therefore, they cannot adopt unless exposed. In fact some farmers would have adopted the pigeonpea varieties if they had been exposed to them, but in this sample adoption rates they are considered as non- adopters. Therefore, an assessment of adoption rates among the exposed subpopulation appears more appealing in terms explaining the potential adoption rates because it somehow addresses the problem of non-exposure bias.

As indicated in Table 2, the adoption rate among the sub-sample of farmers that were aware of pigeonpea is much higher than the adoption rates reported earlier for the whole sample. The overall adoption rate for any pigeonpea among the sub-sample of exposed farmers in 2006/07 season is $55 \%$ compared to a lower adoption rate of $54 \%$ for the whole sample. The two adoption rates are, however, almost equal because there is an almost universal awareness (99 \%) of at least one pigeonpea variety among the sampled households. The finding is consistent with prior expectation in that nonexposure bias diminishes as the number of people exposed to the technology in a population increases.

However, there is a huge difference in adoption rates for improved varieties between the sample adoption rate and the adoption rate within the exposed sub-sample. About $37 \%$ of the farmers that are aware of at least one improved pigeonpea variety adopted the varieties in 2006/07, a rate that is significantly higher than the $14 \%$ adoption rate reported for the whole sample. An interesting observation is that although Thyolo registered a larger proportion ( $40 \%$ ) of farmers that were aware of the improved pigeonpea, the adoption rate among the exposed sub-sample is the lowest at (10\%), while Chiradzulu with the lowest rate of awareness of improved varieties (5\%), registered an adoption rate of $2 \%$ for the total sample and of $33 \%$ within the exposed sub-sample.

While adoption rates for the exposed sample seem more plausible in explaining potential population adoption rates, Diagne (2006) reports that they are likely to significantly over-estimate the population adoption rate due to the positive population selection bias by which the population most likely to adopt gets exposed first. Diagne (2006) points out that the positive selection bias arises from two sources. The first source is the farmer's self-selection into exposure. The second source of selection bias is the fact that researchers and extension workers target their technologies at farmers that are more likely to adopt.

\section{Determinants of exposure to improved pigeonpea varieties}

In this study, only $34 \%$ of the sample households were exposed to a t least one of the improved pigeonpea varieties (ICEAP 040 and ICPL 9145). Based on this we estimate a 
probit regression of factors that affect the propensity of exposure to improved varieties of pigeonpea. Table 3 indicates results from a probit estimation of the determinants of the probability of getting exposed to at least one improved pigeonpea varieties. Several variables show statistically significant coefficients at $5 \%$ level.

Farmer's age may negatively influence access to information about improved varieties. It may be that older farmers are more risk averse and less willing to gather information about new technologies. However, as also noted by Adesina and Forson (1995) the expected result of age is an empirical question, because in some cases older farmers may have more experience in farming and are better able to assess the characteristics of modern technology than younger farmers, and hence a higher probability of adopting the practice. Our results show that the age of household head has a negative coefficient that was statistically significant at $5 \%$ level suggesting that older farmers are less likely to get exposed to the new pigeonpea varieties. This can also be explained by the fact that older farmers may incur higher search costs for the new technologies; hence lack information on the existence of improved pigeon pea varieties (Feder and Slade, 1984).

The proxy variables for access to government extension services - distance to agricultural extension office- was not significant, even though it returned the expected sign. This is consistent with the fact that government extension is no longer a major provider of information.

As indicated in Fig 3, $78 \%$ of the pigeonpea farmers received pigeonpea variety information (local and improved) through contact with other farmers. The other frequently mentioned sources of variety information include parents, seed/grain stockist, Less than $10 \%$ of them reported getting information from government extension workers.

Table 3 Marginal Effects of the determinants of exposure to improved pigeonpea

\begin{tabular}{lll}
\hline Variables & Marginal effects & SE \\
\hline Gender of head (1 = Male, $0=$ Otherwise) & 0.025 & 0.063 \\
Age of head (yrs) & $-.0184^{\mathrm{b}}$ & 0.009 \\
The square of age & 0.000 & 0.000 \\
Education of head (yrs) & -0.005 & 0.008 \\
Household size & 0.089 & 0.056 \\
Distance to the market & $-0.055^{\mathrm{a}}$ & 0.032 \\
Distance to the agricultural extension office & -0.002 & 0.009 \\
Membership in a social//faith based group (1=yes, $0=$ otherwise) & $0.184^{\mathrm{a}}$ & 0.080 \\
Membership in farmer club (1=yes, $0=$ otherwise) & 0.026 & 0.091 \\
Number of years lived in village & $0.004^{\mathrm{b}}$ & 0.002 \\
The value of assets (MK) & $0.039^{\mathrm{a}}$ & 0.020 \\
The Land holding size (ha) & 0.032 & 0.026 \\
Access to credit & 0.091 & 0.067 \\
Balaka & $0.443^{\mathrm{c}}$ & 0.116 \\
Thyolo & $0.535^{\mathrm{c}}$ & 0.062 \\
Number of interviews & 440 & \\
Pseudo R2 & 0.2363 & 132.932 \\
LR Chi 2 & 463.6344 & \\
AlC & & \\
\hline Soure: & & \\
\hline
\end{tabular}

Source: ICRISAT Treasure Legumes/TLII Study (April- May 2008) Key: ${ }^{\mathrm{a}}$ significant at $10 \%$, ${ }^{\mathrm{b}}$ significant at $5 \%$ and ${ }^{\mathrm{c}}$ significant at $1 \%$ 


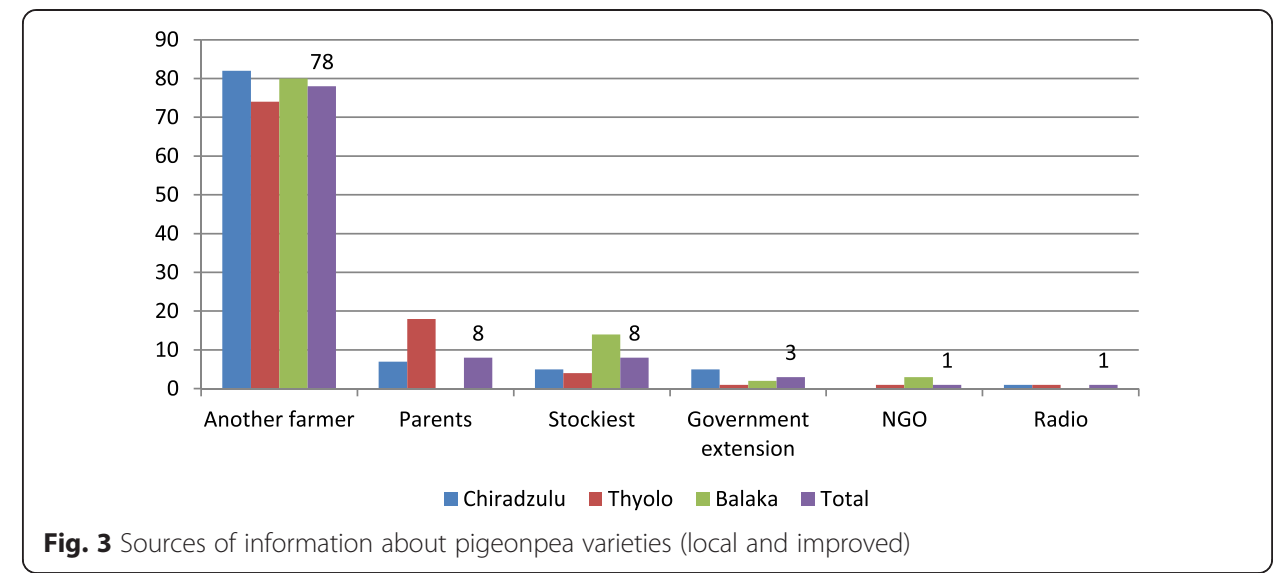

The insignificant role of government in providing extension services is consistent with expectation because there are very few extension workers currently working for government. The other reason could be that government extension services appear to be concentrated on strategic crops such as maize and tobacco.

Since the early 1980s, Malawi pursued a structural adjustment path which as reported by Kumwenda and Madola (2005), also required government to undertake cutbacks in expenditure including funding to the Ministry of Agriculture hence it greatly affected the government provision of extension services. Furthermore, the formal government extension system is biased towards maize, the main staple and tobacco, the main cash crop while legumes such as pigeonpea do not feature highly in the system.

Instead we find that social linkages influence access to information on improved pigeonpea varieties. For example the membership in a social grouping such as a faith based organization has a positive and significant effect on the propensity to get exposed to improved varieties. This finding is also consistent with the debate on the role of social interactions in determining the rate at which technologies are adopted (see for example, Conley and Udry 2005, Manski 2004). While the activities in such groups are not primarily social interactions they shape local social norms and networks that stimulate information sharing and social learning, a process that has a bearing on technology awareness. Acknowledging the role of social interactions in technology diffusion, Rogers (2003) contends that the diffusion process consists of interpersonal network exchanges between those individuals who have already adopted an innovation and those who are then influenced to do so. Such a process can be enhanced by farmer' membership in social grouping that also strengthens their social capital. The number of years of residence in a village has a positive and significant effect on the propensity to get exposed to improved varieties which against provides evidence of the significance of social capital in information sharing.

A proxy variable for access to markets- i.e. the distance to the nearest main market returned a negative and expected sign, and it was significant at $10 \%$ level. The results imply that a percentage increase in the distance from the market to the household reduces the probability of exposure to new variety by about $6 \%$. Thus the further away from markets the less likely a farmer is to be aware of the existence of new pigeonpea varieties. Generally there is a very small commercial market for improved pigeonpea seed to enable seed purchases as farmers often save grain and recycle as seed or 
purchase grain from the local market to use as seed (Tripp 2000). However, in this study about $23 \%$ of the pigeonpea seed was purchased from the market (Fig 4).

These findings underscore the need for further development of the market based seed systems in promoting information diffusion. District dummy variables of Balaka and Thyolo, returned positive and significant coefficients indicating that farmers that resided in the two districts had a higher propensity to get exposed to at least one improved pigeonpea varieties compared to Chiradzulu. Being resident in Balaka and Thyolo increases the probability of exposure to new varieties by $44 \%$ and $54 \%$, respectively. This may be partly attributed to the fact that field trials for the improved pigeonpea varieties were extensively conducted in the two districts before the variety was released and farmers might have continued sharing information about the varieties.

In general, the findings on awareness underscore the need for intensified efforts to create awareness about the existence of improved pigeonpea varieties among farmers. The methods that have proven to be effective are already in place but they require further scaling up. Such methods include (i) on-farm trials; (ii) demonstration plots controlled by agricultural extension agents; (iii) field days for farmers; and (iv) agricultural shows to which farmers are invited and (v) farmer-to-farmer exchange of information (see for example Bentley (2009); Akinsorotan (2009); Davis, et al. (2010)).

\section{Adoption rates for improved Pigeonpea}

The adoption estimates for improved pigeonpea are presented in Table 4. The results show that the sample adoption rates - (joint exposure and adoption rate) is the same for the ATE probit, and the classic probit estimated at (14\%) and that they all yield the same range for the $95 \%$ confidence interval (between $10 \%$ and $17 \%$ ). Again the finding that the sample estimate is the same as the estimate obtained by ATE probit method suggests that the assumptions underlying the models (eg, random sampling, distribution) are plausible in as far as estimating the joint exposure and adoption rate for the whole population and its determinants is concerned (Diagne and Demont, 2007).

The results further indicate that the joint exposure and adoption rate within the presently pigeonpea-exposed subpopulation estimated by the classical probit model (22\%) is different from those estimated by the sample moments and ATE-probit model (39\%). Indeed it can be seen that the classic probit model estimate of $22 \%$ has a $95 \%$ confidence interval ranging between $19 \%$ and $26 \%$, a range that is far below the

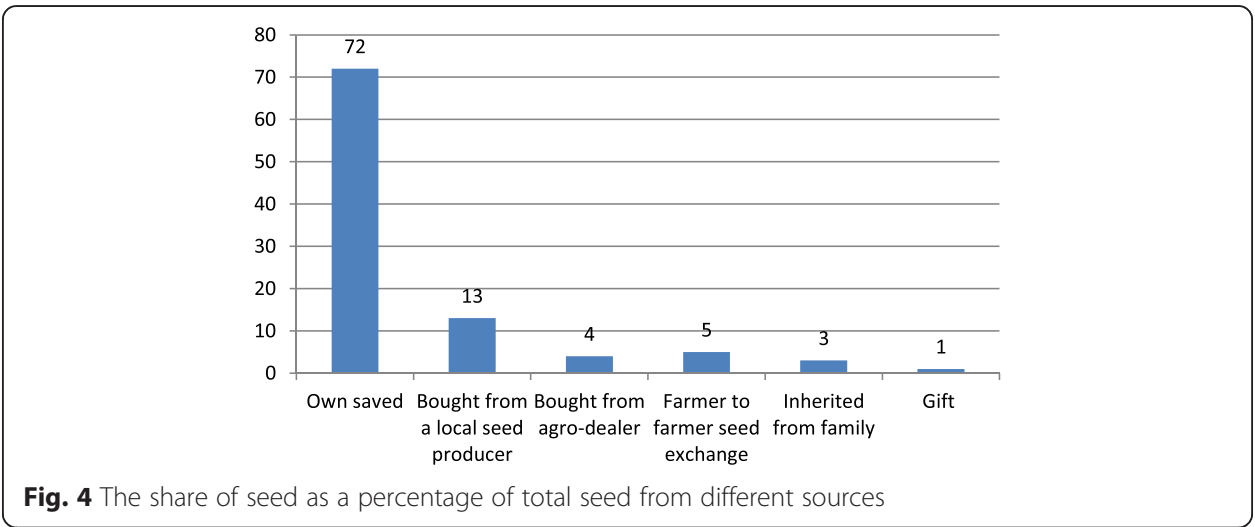


Table 4 Estimates of improved pigeonpea adoption rates (full sample) and their $95 \%$ confidence intervals among all farmers

\begin{tabular}{|c|c|c|c|}
\hline Parameters & $\begin{array}{l}\text { Sample moments } \\
\text { estimate }\end{array}$ & $\begin{array}{l}\text { Classical probit joint } \\
\text { exposure and } \\
\text { adoption model }\end{array}$ & $\begin{array}{l}\text { ATE probit adoption } \\
\text { model }\end{array}$ \\
\hline \multicolumn{4}{|l|}{$\begin{array}{l}\text { Joint exposure and adoption rate (Probability } \\
\text { of knowledge and adoption of at least one } \\
\text { improved pigeonpea variety): }\end{array}$} \\
\hline In the full population & $0.14(0.10-0.16)$ & $0.14(0.10-0.16)$ & $0.14(0.10-0.16)^{* * *}$ \\
\hline $\begin{array}{l}\text { Within the improved pigeonpea-exposed } \\
\text { subpopulation }\end{array}$ & $0.38(0.29-0.48)$ & $0.22(0.19-0.26)$ & $0.39(0.33-0.45)^{* * *}$ \\
\hline \multicolumn{4}{|l|}{$\begin{array}{l}\text { Pigeonpea adoption rate (Probability of } \\
\text { adopting at least one improved pigeonpea): }\end{array}$} \\
\hline In the full population (ATE) & & & $0.41(0.290 .52)^{* * *}$ \\
\hline $\begin{array}{l}\text { Within the improved pigeonpea -exposed } \\
\text { subpopulation (ATE1) }\end{array}$ & & & $0.39(0.33-0.45)^{* * *}$ \\
\hline $\begin{array}{l}\text { Within the sub-population not exposed } \\
\text { to the improved pigeonpea (ATEO) }\end{array}$ & & & $0.42(0.260 .57)^{* * *}$ \\
\hline \multicolumn{4}{|l|}{ Estimated population adoption gap: } \\
\hline Expected non-exposure bias(NEB) & & & $-0.27(-0.37-.17)^{* * *}$ \\
\hline Expected population selection bias (PSB) & & & $-0.17(-0.11-.07)$ \\
\hline
\end{tabular}

Source: ICRISAT Treasure Legumes/TLII Study (April- May 2008)

* Significant at $10 \%$, ** significant at $5 \%$ and ${ }^{* *}$ significant at $1 \%$

consistently estimated value of $41 \%$, a finding that suggests that the classic probit model has a problem of attenuation bias (Yatchew and Griliches, 1985) because the model is based on the full sample without controlling for exposure bias. Diagne and Demont (2007) note that the downward bias of the classical probit model estimate of the probability of joint exposure and adoption for the exposed subpopulation implies that its coefficient estimates are likely to be inconsistent for a model of determinants of adoption. These results, therefore, represent the expected joint exposure and adoption rate for the population which is not the desirable parameter of interest in most adoption studies.

The desirable parameter in adoption studies is the full population adoption rate (ATE) which provides an estimate of the potential demand of the pigeonpea technology by the target population. The full population adoption rate for improved pigeonpea is estimated to be $41 \%$ for ATE probit method. This implies that the pigeonpea adoption rate in Malawi could have been $41 \%$ in 2007 if the whole population had been exposed to improved varieties of pigeonpea, instead of the joint exposure and adoption rate of $14 \%$. Thus when compared to the current sample adoption rate of $14 \%$, there is a substantial population adoption gap of $27 \%$ due to the population's incomplete exposure to the pigeonpea varieties. The estimated adoption gap is statistically significantly different from zero at $1 \%$ level. This finding implies that there is potential for increasing adoption rate by $27 \%$ once all farmers become aware of at least one improved pigeonpea variety.

The adoption rate within a sub-population of farmers that are exposed to at least one improved pigeonpea variety (ATE1) is estimated to be $39 \%$ for the ATE parametric probit model, while the estimated potential adoption rate within the sub-population not yet exposed to pigeonpea variety (ATE0) is $42 \%$ for the parametric probit model. The estimated population selection bias (PSB) is $2 \%$ but it is not significantly different 
from zero. This implies that the adoption probability for a farmer belonging to the subpopulation of informed farmers is not significantly different from the adoption probability for any farmer within the population. Nonetheless the negative PSB indicates that the farmers exposed to the improved pigeonpea varieties are less likely to adopt at least one improved pigeonpea variety than any farmer randomly selected from the population. Since the PSB is insignificant, we cannot reject the null hypothesis that a farmer selected randomly within a population has the same probability of adopting improved pigeonpea varieties as a farmer selected within the sub-population of those informed about improved pigeonpea varieties.

The above adoption rates are based on full sample of farmers that included three groups; thus, (i) non-pigeonpea growers, (ii) pigeonpea growers that did not adopt improved varieties, and (iii) pigeonpea growers that adopted improved varieties. Therefore the results on potential adoption rates measure the adoption probability of improved pigeonpea varieties by a farmer randomly selected for a population composed of the three groups described above.

\section{Determinants of adoption of improved pigeonpea varieties}

Results on the determinants of improved pigeonpea adoption for the classic "adoption" model, and ATE probit model are presented in Table 5. The results are presented in the form of marginal effects. There are striking differences in the magnitude of the coefficients as well as their marginal effects between the two models. In general the

Table 5 Determinants of adoption of improved pigeonpea- Marginal effects

\begin{tabular}{|c|c|c|c|c|}
\hline \multirow[t]{2}{*}{ Variables } & \multicolumn{2}{|l|}{ ATE corrected } & \multicolumn{2}{|c|}{ Classical adoption } \\
\hline & Marginal effect & SE & Marginal effect & SE \\
\hline Gender of head ( $1=$ Male, $0=$ Otherwise) & $-0.282^{* *}$ & 0.139 & -0.042 & 0.035 \\
\hline Age of head (yrs) & $0.048^{* *}$ & 0.023 & -0.001 & 0.004 \\
\hline The square of age & 0.000 & 0 & 0 & 0 \\
\hline Education of head (yrs) & 0.030 & 0.016 & 0.001 & 0.004 \\
\hline Household size & -0.007 & 0.113 & 0.019 & 0.028 \\
\hline Distance to the village market & 0.006 & 0.03 & -0.006 & 0.006 \\
\hline Distance to the agricultural office & -0.016 & 0.017 & $-0.008^{* *}$ & 0.004 \\
\hline Membership is a faith group ( $1=$ yes, $0=$ no) & $-0.276^{* *}$ & 0.119 & -0.04 & 0.031 \\
\hline Membership in farmer club $(1=$ yes, $0=$ no $)$ & 0.223 & 0.193 & 0.081 & 0.074 \\
\hline Number of years lived in village & -0.007 & 0.004 & 0.001 & 0.001 \\
\hline The value of assets (MK) & 0.002 & 0.042 & 0.015 & 0.009 \\
\hline The Land holding size (ha) & -0.033 & 0.06 & 0.001 & 0.02 \\
\hline Access to credit & $.410^{* * *}$ & 0.11 & $0.146^{* *}$ & 0.045 \\
\hline Balaka & 0.359 & 0.251 & $0.289 * *$ & 0.106 \\
\hline Thyolo & -0.351 & 0.189 & 0.059 & 0.05 \\
\hline Number of interviews & 152 & & 440 & \\
\hline Pseudo R2 & 0.4121 & & 0.3827 & \\
\hline LR Chi 2 & 73.9007 & & 72.314 & \\
\hline $\mathrm{AlC}$ & 156.2294 & & 269.215 & 0.05 \\
\hline
\end{tabular}

Source: ICRISAT Treasure Legumes/TLII Study (April- May 2008) Key: * significant at $10 \%$, ** significant at $5 \%$ and ${ }^{* * *}$ significant at $1 \%$ 
marginal effects of the ATE probit model are larger in absolute values than those of the classic "adoption" model. The observed findings are consistent with the theoretical expectation in that as reported by Diagne and Demont (2007), the conditional mean "adoption" function estimated in the classical adoption model is equal to the true population average conditional adoption function (the "true" population adoption function) multiplied by the probability of being aware of the technology. Hence, for a factor determining adoption alone and not awareness, its marginal effect calculated from the classical "adoption" model is equal to its marginal effect from the true adoption model multiplied by the conditional probability of awareness, a quantity always between 0 and 1 and usually very small when not many farmers are aware of the technology. It is also important to note that some coefficients are significant in both models while some are significant only in the ATE probit model. Results show that factors such as gender of the head of household, the age of a farmer and access to credit contribute significantly to the probability of adopting improved pigeonpea adoption.

The coefficient for gender of household head is negative and significant at $5 \%$ suggesting that the probability of adopting at least one improved pigeonpea variety diminishes with being a male farmer. Being a male headed household reduces the propensity to adopt improved pigeonpea varieties by about $28 \%$. This is apparently consistent with previous assertions from farmers in Malawi where women farmers prefer to pigeonpea cultivation and often refer to pigeonpea as "our beef" a reference to the crops high protein content, and frequently sell the crop as a fresh.

The age of the farmer returned a positive and significant marginal coefficient suggesting that a percentage increase in age increases the propensity to adopt improved varieties by 5 percent. The findings might be explained by the fact that although older farmers face higher search costs for information on new technologies which reduces their exposure, once they overcome the information barrier, older farmers are quick to adopt them because they have a higher resource endowment than young farmers. This observation is quite consistent with the economic constraints paradigm explained by Feder and Slade, (1984). In our case it might suggest that older farmers are able to purchased improved seed for pigeonpea which young farmers cannot due to financial constraints. Yet another explanation could be that young people have more viable options or alternative investments hence may delay adoption of improved varieties.

The membership in a faith based group returned a negative and significant marginal effect indicating that although more likely to know about the existence of improved pigeonpea varieties, membership in a faith based social grouping lowers the propensity to adopt pigeonpea by $27 \%$. One possible explanation for the positive coefficient in the exposure model can be drawn from innovation-diffusion paradigm, while the explanation for the negative coefficient in the adoption model can be drawn from the economic constraint paradigm of the adoption model. The innovation-diffusion paradigm is based on the assumption that the technology is technically and culturally appropriate but the problem of adoption is one of asymmetric information and very high search costs (Feder and Slade, 1984). The economic constrain paradigm states that input fixity in the short run, such as access to credit, land, labor or other critical inputs limits production flexibility and conditions technology adoption decisions (Uaiene et al. 2009). This finding could suggest that once farmers with membership in faith based organizations overcome information search costs and have access information on improved 
varieties, they are unable to overcome other economic and non-economic constraints to be able to adopt improved pigeonpea varieties.

Again, consistent with the economic constraint paradigm of adoption models, access to credit returned an expected positive and significant marginal effect. Indeed the household that borrowed some money from the lending institution increased the propensity of adopting improved pigeonpea by about $40 \%$. Seeds are not a lumpy investment, but credit and cash constraints can be important because adoption of improved pigeonea might entail purchasing seed, hiring extra labour which increases the cost of production. With the availability of credit a household can purchase improved seed and hire extra labour. In this study only $16 \%$ of the farmers indicated that they borrowed money from either credit institutions or informal institutions, despite the high demand for credit. This finding suggests that there exists a great scope for increasing the cultivation of improved pigeonpea through an improved access of farmers to credit markets.

\section{Conclusions}

This paper has provided estimates of actual and potential adoption rates and the determinants of adoption for the improved pigeonpea varieties in Malawi and has shown the importance of appropriately controlling for exposure and selection bias when assessing the adoption rates of a technology and its determinants. We find that improved pigeonpea adoption rates in Malawi could have been up to $41 \%$ in 2007 instead of the observed sample adoption rate of $14 \%$ if the whole population was exposed to the improved pigeonpea varieties. The non-exposure bias of $27 \%$ suggests that there is potential for increasing the adoption rate of improved pigeonpea by $27 \%$ if its diffusion to the population can be completed and if other economic constraints are addressed.

Moreover, the observation that only a third (34\%) of the farmers was aware of at least one of the improved pigeonpea varieties underscores the urgent need for scaling up efforts disseminate information about improved pigeonpea varieties and their potential benefits among farmers. The methods that have proven to be effective are already in place but they require further scaling up. Such methods include on-farm trials, demonstration plots controlled by agricultural extension agents, field days for farmers, and agricultural shows to which farmers are invited.

The study has shown that the exposure to improved pigeonpea varieties and their adoption by farmers is influenced by a number of other factors and that in some cases factors affecting the two outcomes (exposure and adoption) are different. The probability of a farmer's awareness of at least one improved pigeonpea variety was higher among younger farmers, members of faith based organization and those that have lived longer in the village of residence at the time of the survey, whereas adoption propensity was higher among older farmers and women. Moreover, signifying the presence of economic constraints, the study has shown that the propensity of cultivating at least one improved pigeonpea variety is high among farmers that have access to credit services. These findings point to the importance of improving farmer's access to financial markets that enable them to acquire credit to purchase improved seed. The policy implication is that supporting farmers, particularly, women with credit and extension services would significantly increase their participation in the cultivation of improved pigeonpea. 


\section{Endnotes}

${ }^{1}$ The non-exposure bias results from the fact that farmers who have not been exposed to a new technology cannot adopt it even if they might have done so if they had known about it (Diagne, 2006).

${ }^{2}$ This section largely draws from Diagne and Demont (2007)

${ }^{3}$ In this study the adoption outcome is the adoption status (a dichotomous 0-1 variable).

${ }^{4}$ Note that as discussed earlier, the joint exposure and adoption parameter (JEA) is consistently estimated by the sample average of the observed adoption outcome values: $J \hat{E} A=\frac{1}{n} \sum_{i=1}^{n} y_{i}$.

${ }^{5}$ Malawi is divided into eight Agricultural Development Divisions (ADDs) that form different agro-ecological zones. These ADDs lie within the three regions of the country. The ADDs constitute the primary management unit of extension services. The ADDs are subdivided into Rural Development Projects (RDPs), which are further subdivided into Extension Planning Areas (EPAs). The EPAs are further sub-devided into sections Extension agents called Field Assistants supervise at the section level.

${ }^{6}$ In this study access to credit combines both formal credit from the bank or microfinance institution and credit from informal sources such as friends and relatives.

Competing interests

The authors declare that they have no competing interests.

\section{Authors' contributions}

FS participated in data collection, analysis and drafting of the manuscript. SA participated in the draftig of the manuscript. TA participated in the designe of the study including financing data collection and providing technichal advice on the analytical techniques. All authors read and approved the final manuscript.

\section{Acknowledgements}

We are grateful for the financial support from IFAD for enabling the collection of data and collaborating institutions from Malawi such as the Centre for Agricultural Research and Development, the Ministry of Agriculture, and the National association for Small holder Farmers (NASFAM) for coordinating the collection of data

\section{Author details}

${ }^{1}$ International Maize and Wheat Improvement Center (CIMMYT), ICRAF House, United Nations Avenue, 1041-00621, Nairobi, Gigiri, Kenya. ${ }^{2}$ Agricultural Development Economics Division (ESA) Food and Agriculture Organization of the United Nations (FAO), Rome, Italy.

Received: 10 January 2015 Accepted: 18 February 2016

Published online: 27 February 2016

\section{References}

Abate T, Alene AD, Bergvinson D, Shiferaw B, Silim S, Orr A, Asfaw S (2012) Tropical Grain Legumes in Africa and South Asia. Knowledge and Opportunities. International Crops Research Institute for the Semi-Arid Tropics, Nairobi, Kenya Adesina AA, Forson JB (1995) Farmers' perceptions and adoption of new agricultural technology: Evidence from analysis in Burkina Faso and Guinea, West Africa. Agric Econ 13:1-9

Akinsorotan AO (2009) Impact of Field Day on Oil Palm Farmers Knowledge. J Soc Sci 20(1):67-70

Bentley JW (2009) Impact of IPM extension for small-holder farmers in the tropics. In: Peshin R, Dhawan AK (eds) Integrated pest management: dissemination and impact. Springer, New York, NY, pp 333-346

Conley, T. and C. Udry (2005) Learning about a new technology: Pineapple in Ghana," Working paper, University of Chicago and Yale University.

Davis K et al (2010) Impact of farmer field schools on agricultural productivity and poverty in East Africa IFPRI Discussion Paper 00992. International Food Policy Research Institute, Washington, D.C

Diagne A (2006) Diffusion and adoption of NERICA eice varieties in Côte d'Ivoire. Dev Econ XLIV-2:208-31

Diagne 2012 Adoption: A Stata routine for consistent estimation of population technology adoption parameters. www.stata. com/meeting/sandiego12/materials/sd12_diagne.pdf

Diagne A, Demont M (2007) Taking a New look at Empirical Models of Adoption: Average Treatment Effect estimation of Adoption rate and its Determinants. Agric Econ 37(2-3):201-210

Feder G, Slade R (1984) The acquisition of information and the adoption of new technology. Amer J of Agric Econ 66(2):312-320 
Freeman HA, Van der Merwe PJA, Subrahmanyam P, Chiyembekeza AJ, Kaguongo W (2002) Assessing adoption potential of new groundnut varieties in Malawi. Exp Agric 38(2):211-221. ISSN 0014-4797.

Høgh-jensen H, Myaka FA, Sakala WD, Kamalongo D, Ngwira A, Vesterager JM, Odgaard R, Adu-gyamfi JJ (2007) Yields and qualities of pigeonpea varieties grown under smallholder farmers' conditions in eastern and southern Africa. Afric J Agric Res 2:269-278

Kumwenda I, Madola M (2005) The status of contract farming in Malawi, Paper submitted to the Food, Agriculture and Natural Resources Policy Analysis Network

Malawi government (2006) The Crops Production Policy

Manski C (2004) Social learning from private information: The dynamics of the selection problem. Rev Econ Stud 71:443-458

Muwalo ES, Palian A, Nkahata B, Ndawala RS, Ng'oma MD, Ritchie M, Nyandule Phiri GSVK (1999) Assessment of pigeonpea pest, storage methods and control methods used on farm in Malawi. Presented at the 1999 annual rsearch project meetings at Natural Resources College 4-7 August 1999, Lilongwe, Malawi

Orr, A and Kabombo, B Roth, C Harris, D and V Doyle (2013) Testing Integrated Food Energy Systems: Improved Stoves and Pigeon Pea in Southern Malawi. Socioeconomics Discussion Paper Series 8. Socioeconomics Discussion Paper Series]

Orr A, Kabombo B, Roth C, Harris D, Doyle V (2015) Adoption of integrated food-energy systems: improved cookstoves and pigeonpea in southern. Malawi Expl Agric 51(2):191-209

Orr. A and S.Orr. 2002. Agriculture and micro enterprise in Malawi's rural south. Agricultural Research \& Extension Network Paper No. 119

Phillips J (2008) A comparative econometric study of the barriers to adoption of New Rice Crops (NERICAs) in West Africa. MSc dissertatio n, School of Oriental and African Studies, University of London, UK.

Rogers EM (2003) Diffusion of innovations, 5th edn. Free Press, New York

Rosenbaum PR, Rubin DB (1983) The central role of the propensity score in observational studies for causal effects. Biometrika 70(1):41-55

Rubin D (1974) Estimating Causal Effects of Treatments in Randomized and Non-randomized Studies. J Educ Psychol 66:688-701

Simtowe F, Bekele S, Menale K, Monyo E, Silim S, Muricho G (2009) Assessment of the Current Situation and Future Outlooks for the groundnut Sub-Sector in Malawi. International Crops Research Institute for the Semi Arid Tropics, Nairobi

Snapp SS, Rohrbach DD, Simtowe F, Freeman HA (2002) Sustainable soil management options for Malawi: can smallholder farmers grow more legumes? Agric Ecosyst Environ 91:159-174

Uaiene R.N., C. Arndt and W. A. Masters (2009) Determinants of agricultural technology adoption in Mozambique; Discussion papers No. 67E.Accessed at http://docplayer.net/8027694-Determinants-of-agricultural-technology-adoption-inmozambique.html on March 2010

Wooldrige J (2002) Econometric analysis of cross section and panael data. TheMIT press, Cambridge, Massachusetts, USA

Yatchew A, Griliches Z (1985) Specification Error in Probit Models, The Review of Economics and Statistics. Rev Econ Stat 67(1):134-39, MIT Press

\section{Submit your manuscript to a SpringerOpen ${ }^{\circ}$} journal and benefit from:

- Convenient online submission

- Rigorous peer review

- Immediate publication on acceptance

- Open access: articles freely available online

- High visibility within the field

Retaining the copyright to your article 